Proceedings

\title{
High Resolution Historical Topography: Getting More from Archival Aerial Photographs ${ }^{\dagger}$
}

\author{
Simone Seccaroni, Michele Santangelo *, Ivan Marchesini, Alessandro C. Mondini and \\ Mauro Cardinali \\ Consiglio Nazionale delle Ricerche-Istituto di Ricerca per la Protezione Idrogeologica (CNR-IRPI), \\ Via della Madonna Alta, 126-06128 Perugia, Italy; s.seccaroni@virgilio.it (S.S.); ivan.marchesini@irpi.cnr.it (I.M.); \\ alessandro.mondini@irpi.cnr.it (A.C.M.); mauro.caradinali@irpi.cnr.it (M.C.) \\ * Correspondence: michele.santangelo@irpi.cnr.it \\ + Presented at the 2nd International Electronic Conference on Remote Sensing, 22 March-5 April 2018; \\ Available online: https://sciforum.net/conference/ecrs-2.
}

Published: 22 March 2018

\begin{abstract}
High resolution elevation data is fundamental information for multiple applications in geomorphology spanning from visual analyses to modeling. Nowadays, gathering of high-quality elevation data relies on multiple sensors and technologies that can be mounted on terrestrial, aerial and satellite platforms. In the last few years, the Structure from Motion (SfM) algorithms have made the acquisition of high and very-high resolution elevation data from optical images acquired with high overlapping rates at virtually no cost possible. Such a feature made it possible to exploit remote sensing archival imagery to build historical topographic information with unprecedented detail. However, despite the increasing number of applications of SfM algorithms in the scientific literature, still little has been done in terms optimization and quality evaluation of the results. We have applied the SfM algorithm developed in the photogrammetric open source software MicMac to six black and white aerial photographs taken in 1954 at 1:33,000 in a mountainous and steep area in Central Italy. The aim of the experiment consists of a quantitative evaluation of the digital surface models obtained for different scanning settings.
\end{abstract}

Keywords: aerial photographs; digital photogrammetry; open source; MicMac; high-resolution topography; GNSS

\section{Introduction}

Photogrammetry allows the reconstruction of the shape and metric of an investigated object, starting from measurements of points on photographs. The recent development of photogrammetric algorithms such as Structure from Motion (SfM) and multi-view-stereo (MVS) algorithms opens up an unprecedented possibility to derive high-resolution Digital Surface Models (DSMs) from archival images despite the common lack of the calibration certificates [1-4].

Although the number of papers dealing with SfM algorithms in the scientific literature is increasing, more work still needs to be done to evaluate the quality of the resulting DSMs and to optimize the digitalization process $[1,5]$. In this work, we test how photographs' digitalization settings (geometric and radiometric resolution) affect the accuracy of the output DSMs obtained applying the same photogrammetric processing chain. We processed six archival aerial photographs taken in 1954 at 1:33,000 scale in a mountainous and steep area in Central Italy, whose topography represents a challenge for producing photogrammetric DSMs.

Both proprietary and open source photogrammetric software applications exist, which are used for work and research [6-8]. Unlike proprietary software, however, open source gives the possibility to examine $[9,10]$, modify and redistribute the algorithms, and is particularly suitable for research 
reproducibility and replicability [11] and closer to the general concept of open science [12]. For this work, we have adopted MicMac, an open source photogrammetric software that implements SfM and and MVS algorithms [13].

\section{Study Area}

The study area is a $35 \mathrm{~km}^{2}$ wide area in the Northern Apennines, Central Italy. The area shows the common features of a mountainous region: elevation spans between 610 and $1560 \mathrm{~m}$ a.s.l., and the highest slope reaches $90^{\circ}$. Furthermore, due to the bedding attitude of the rocks that crop out in the study area, overhanging sandstone and limestone cliffs are a diffuse feature. The relative relief within the study area is particularly high. This is due to the presence of five major valleys that converge in the eastern part of the study area (Figure 1). Landcover is mainly wooded and scarcely built up, with few and sparse cultivated fields. Above $1200 \mathrm{~m}$ a.s.l., landcover is mainly bare soil or grass.

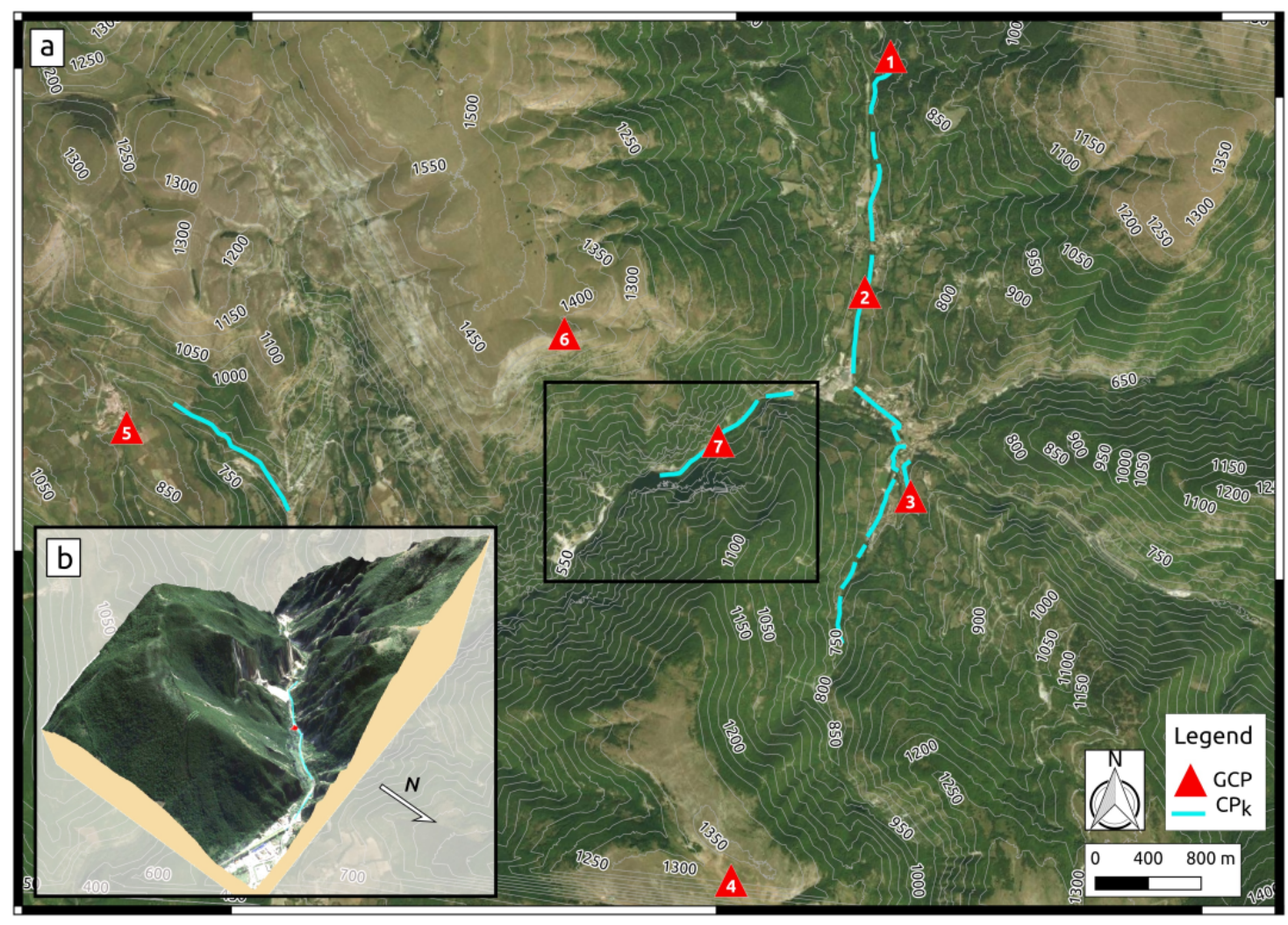

Figure 1. Study area. (a) main map. Red triangles indicate the locations of the Ground Control Points (GCPs); blue lines indicate the path followed to collect control points in kinematic mode $\left(C P_{K}\right)$; (b) perspective view of the central portion of the study area.

\section{Materials}

The area of interest is covered by six black and white $23 \times 23 \mathrm{~cm}$ aerial photographs (printings of original negative films), acquired in September 1954 at approximately 1:33,000 scale with a calibrated focal length of $153.78 \mathrm{~mm}$, using a FAIRCHILD camera (Fairchild Camera and Instrument Company, $\mathrm{DE}$, Unated States). The photographs belong to two strips, which have an overlap of $60 \%$ and a sidelap of $40 \%$.

For the computation of the DSMs, we used an Asus G750JX laptop (Taipei, Taiwan), with a IntelC Core $^{\mathrm{TM}}$ i7 4700HQ 8-cores processor (Santa Clara, CA, Unated States), 24 GB of DDR3 RAM memory and NVIDIA ${ }^{\circledR}$ GeForce ${ }^{\circledR}$ GTX 770M GPU (Santa Clara, CA, Unated States) graphic chip-set with 3 GB DDR5 dedicated memory. 
The digitalization of the aerial photographs was carried out by the Epson expression 10,000 XL scanner (Suwa, Japan). Its maximum geometric resolution is $2400 \mathrm{dpi}$ at a maximum of 16 bit in gray-scale and 32 bit in color mode.

The survey to collect ground control points (GCPs) and control points (CPs) in kinematic mode was carried out using the GNSS (Global Navigation Satellite System) receiver Leica Zeno 20 (Wetzlar, Germany), mounting the external antenna Leica AS10, and it was used in RTK (Real Time Kinematic) mode, which allowed for a centimetric accuracy.

The software used at different steps of this work were: (i) SilverFast 6.6; (ii) MicMac [14].

\section{Procedure to Obtain the Photogrammetric DSM}

The first step of the procedure consisted of scanning the photographs. Each photograph was acquired at 400, 800, 1600 and 2400 dpi in gray-scale both at 8 and 16 bit using SilverFast software (version 6.6, LaserSoft Imaging, Kiel, Germany), for a total of eight datasets. Images were then cropped using a rectangle mask, with the sides tangent to the fiducial marks.

In the second step, the images exif proprieties were edited (MicMac command SetExif) to provide information on focal length $F_{m m}$ and equivalent focal length $F_{35}$ for the internal calibration. The focal value was available from the distributor website [15]. The $35 \mathrm{~mm}$ equivalent focal length $\left(F_{35}\right)$ was computed as follows: $F_{35}=F_{m m} \times W_{35} / W_{\text {film }}$, where $W_{35}$ is the film width (in millimeters) for a $35 \mathrm{~mm}$ camera, and $W_{\text {film }}$ is the film width of the acquisition camera (in millimeters). In this case, $F_{35}$ was equal to $23.86 \mathrm{~mm}$.

The third step consists of the tie points definition (homologous pixels automatically detected across different images) through an image matching process performed by the MicMac tool Tapioca.

In the next step, masks can be created to prevent MicMac from unnecessary computation. The graphical interface tool used is SaisieMasqQT. Then, tie-points are filtered out by HomolFilterMasq.

The bundle block adjustment (BBA) is performed in the fifth step by the MicMac command Tapas, an interface to the more complex tool Apero [16].

In the sixth step, GCPs have to be identified and selected on each image by a graphic interface (tool SaisieAppuisInitQT). The GCP ground absolute coordinates and the user-defined uncertainties are stored in a .txt file, then converted in a .xml file by the tool GCPConvert.

In the next step, a rigid transformation from the model coordinate system Arbitrary to the absolute coordinate system GroundInt is performed by the tool GCPBascule. Subsequently, a second BBA that fits tie points and GCPs is performed by the command Campari that calls the tool Apero.

Lastly, once the sparse point cloud has been generated, MicMac can proceed to the dense matching by the tool Malt. Finally, the dense point cloud is exported in .ply format by Nuage2Ply.

\section{Ground Control Points}

To further constrain the model, GCPs were collected by a GNSS survey. When collecting GCPs, care was taken to avoid cluster effects, and covering as homogeneously as possible the study area, also in elevation [17]. Particular attention was paid to the portion of the area covered by the black outlined rectangle in Figure 1. Due to the poorly built up landscape around the only municipality in the area (Visso) in 1954, and the difficulty in accurately finding the corresponding location of GCPs in today's landscape, most of the GCPs were selected at crossroads or on structures (Figure 1). For each of the seven GCPs collected, longitude, latitude and elevation above ETM (Earth Gravitational Model) 2008 geoid were acquired using the available GNSS equipment in RTK mode. Elevation was converted to ITA 2005 geoid, more accurate for Italy.

To collect CPs for the DSMs validation, a GNSS survey was conducted in the field using the true kinematic method. The antenna was mounted on a car, and the frequency of acquisition set to one point every $10 \mathrm{~m}$. The over 1000 points in the area were collected along two roads approximately running in the N-S and E-W directions (Figure 1). The points with uncertainties greater than $10 \mathrm{~cm}$ 
were filtered out, obtaining a robust set of elevation data used as control points $\left(\mathrm{CP}_{K}\right)$ to validate the output DSMs.

\section{Results and Discussion}

Table 1 summarizes the results of the experiment presented. For reference, the first four rows describe the characteristics of the eight datasets.

When considering the number of tie points generated, no appreciable difference is observed across color depths. The highest number of tie points were obtained for $800 \mathrm{dpi}$ (both 8 and 16 bit) images. Furthermore, a decreasing trend in BBA error is observed across scanning resolutions. However, the improvement between the 1600 and 2400 dpi datasets is negligible, both at 8 and 16 bit.

Table 1. Results for the eight datasets. GSD, Ground Sampling Distance; BBA, Bundle Block Adjustment; P.E., Projection Error; GCP, Ground Control Point; DSM, Digital Surface Model; H-MAE, Mean Absolute Error of residuals in elevation; H-RMSE, Root Mean Square Error along elevation. Units of measure not belonging to the SI: $d p i$, dots per inch; $p x$, pixels; $p / m^{2}$, points per square meter; $m i n$, minutes. Dataset names: $800 \mathrm{~g} 16$ indicates an image scanned at $800 \mathrm{dpi}$, in gray-scale, and at 16 bit.

\begin{tabular}{|c|c|c|c|c|c|c|c|c|}
\hline Dataset Name & $400 \mathrm{~g} 8$ & $800 \mathrm{~g} 8$ & 1600g8 & $2400 \mathrm{~g} 8$ & $400 \mathrm{~g} 16$ & $800 \mathrm{~g} 16$ & $\operatorname{l600g16}$ & $2400 \mathrm{~g} 16$ \\
\hline \multicolumn{9}{|l|}{ Scanned images } \\
\hline Resolution $[\mathrm{dpi}]$ & 400 & 800 & 1600 & 2400 & 400 & 800 & 1600 & 2400 \\
\hline Color depth [bit] & 8 & 8 & 8 & 8 & 16 & 16 & 16 & 16 \\
\hline Pixel size $[\mu m]$ & 56 & 28 & 14 & 9 & 56 & 28 & 14 & 9 \\
\hline Approx. GSD $[m]$ & 1.91 & 0.95 & 0.48 & 0.32 & 1.91 & 0.95 & 0.48 & 0.32 \\
\hline \multicolumn{9}{|l|}{ Sparse point cloud } \\
\hline Tie points [thousands] & 62.1 & 79.9 & 75.4 & 66.6 & 62.4 & 79.7 & 75.4 & 66.8 \\
\hline BBA P.E. $[p x]$ & 0.32 & 0.459 & 0.71 & 0.981 & 0.319 & 0.469 & 0.725 & 0.981 \\
\hline BBA \& GCP, P.E. $[p x]$ & 0.363 & 0.512 & 0.683 & 0.949 & 0.362 & 0.537 & 0.789 & 0.948 \\
\hline BBA \& GCP, P.E. $[m]$ & 0.69 & 0.49 & 0.33 & 0.3 & 0.69 & 0.51 & 0.38 & 0.3 \\
\hline \multicolumn{9}{|l|}{ Dense point cloud } \\
\hline Mean density $\left[\mathrm{p} / \mathrm{m}^{2}\right]$ & 0.33 & 1.33 & 5.31 & 11.74 & 0.33 & 1.33 & 5.3 & 11.77 \\
\hline \multicolumn{9}{|l|}{ DSM } \\
\hline DSM Resolution $[\mathrm{m}]$ & 2 & 1 & 0.5 & 0.35 & 2 & 1 & 0.5 & 0.35 \\
\hline \multicolumn{9}{|l|}{ Computation time } \\
\hline Tapioca $[\mathrm{min}]$ & 6 & 21 & 30 & 40 & 6 & 22 & 28 & 40 \\
\hline Malt $[\mathrm{min}]$ & 23 & 87 & 449 & 1294 & 19 & 84 & 430 & 1175 \\
\hline \multicolumn{9}{|l|}{ Internal coherence } \\
\hline 3D MAE $[m]$ & 0.27 & 0.11 & 0.20 & 0.27 & 0.36 & 0.16 & 0.23 & 0.27 \\
\hline 3D RMSE $[m]$ & 0.50 & 0.16 & 0.28 & 0.40 & 0.59 & 0.20 & 0.40 & 0.40 \\
\hline \multicolumn{9}{|l|}{ Model validation } \\
\hline Mean $[m]$ & -0.81 & -0.2 & -1.08 & -0.89 & -1.01 & -0.21 & -1.18 & -0.94 \\
\hline Median $[m]$ & -0.48 & -0.36 & -0.92 & -0.77 & -0.48 & -0.36 & -0.92 & -0.77 \\
\hline Standard dev. $[m]$ & 2.51 & 2.11 & 1.66 & 1.79 & 2.65 & 1.97 & 1.7 & 1.85 \\
\hline H-MAE $[m]$ & 1.96 & 1.66 & 1.52 & 1.54 & 2.06 & 1.54 & 1.6 & 1.58 \\
\hline H-RMSE $[m]$ & 2.64 & 2.11 & 1.98 & 2 & 2.84 & 1.97 & 2.07 & 2.07 \\
\hline
\end{tabular}

Table 1 also reports the running time of Tapioca and Malt, the most demanding (parallelized) tools of the entire pipeline. The time increase trend is steeper for Malt compared to Tapioca. Therefore, processing images at high geometric resolutions implies more time expense due to the dense matching process. On the other hand, it is observed that increasing the radiometric resolution does not lead to running time increase, neither for Tapioca, nor for Malt.

The distance between the seven GCPs and the location of the same GCPs computed by the model [13] can be considered as an indicator of its internal coherence. In detail, Table 1 shows the two indicators MAE and RMSE. Inspection of Table 1 reveals that (i) g8 datasets have residuals comparable 
to or slightly smaller than the corresponding g16 datasets; (ii) the $800 \mathrm{~g} 8$ dataset shows the lowest residuals; and (iii) the minimum values of RMSE and MAE were obtained for $800 \mathrm{dpi}$ (both for 16-bit and 8-bit scanned images). Unexpectedly, we notice that increasing color depth does not necessarily correspond to an increased internal coherence. We hypothesize that this can be due to the fact that the original images are grey-scale printed photographs. Since previous research indicates that 16-bit acquisition is advised as a best practice [18], based on our results, further tests should be carried out to further look into this topic.

A total of eight dense point clouds were projected into DSMs, whose resolution was set close to the GSD of the starting images (Table 1).

To evaluate the accuracy of the eight DSMs, we computed the difference between the elevation of each $\mathrm{CP}_{K}$ and the elevation of each DSM at the planimetric location of each $\mathrm{CP}_{K}$. Outliers were singled out and filtered according to a three-sigma $(3 \sigma)$ error criterion. Statistics of residuals distributions are shown in the last section of Table 1.

Inspection of model validation data (Table 1) shows that $800 \mathrm{~g} 8$ is the best dataset in terms of mean value proximity to zero, which can be taken as an indicator of small systematic error. Anyway, as already mentioned above, $1600 \mathrm{~g} 8$ has the smallest standard deviation, which can be taken as an indicator of good relative accuracy. Moreover, $1600 \mathrm{~g} 8$ has the smallest root mean squared error (RMSE), which takes into account both random and systematic error [19]. Finally, 1600g8 has also the smallest mean absolute error (MAE), which is an even more important quality indicator than RMSE, according to some authors [20]. To check for normality of the two best distribution candidates $800 \mathrm{~g} 8$ and $1600 \mathrm{~g} 8$, we made a one-sample Kolmogorov-Smirnov test. The $800 \mathrm{~g} 8$ dataset seems better normally distributed, showing a maximum distance value of 0.20 compared to the 0.30 of the $1600 \mathrm{~g} 8$ dataset.

Overall, considering the model internal coherence, the mean point density of the point clouds, and the results of the model validation (Table 1), it emerges that the optimal performance was obtained at $1600 \mathrm{dpi}$ for images scanned at $8 \mathrm{bit}$, whereas it was obtained at $800 \mathrm{dpi}$ for images scanned at 16 bits. When compared to the computation time, it is also clear that a low increase in the internal model of $2400 \mathrm{dpi}$ ( 8 and $16 \mathrm{bit}$ ) corresponds to a computation time way too large compared to the 1600 dpi datasets. Such evidence underlines that acquisition at $2400 \mathrm{dpi}$ appears inconvenient, even for high-performance machines. Moreover, Table 1 shows that the number of tie points automatically detected by Tapioca decreases with the increasing scanning resolution higher than $800 \mathrm{dpi}$.

\section{Conclusions}

This work quantified the influence of acquisition of archive aerial images on the accuracy of DSMs produced applying photogrammetric algorithms, and hence can help to define the best acquisition mode to get the most from archival aerial photographs.

Limited to the historical aerial photographs used in this study (available for the entire Italian territory), results revealed that the optimal scanning geometrical resolution is between 800 and $1600 \mathrm{dpi}$, and that the radiometric resolution neither affects computation time nor provides any quality improvement of the final DSMs.

The photographs used in this experiment belong to an extensive aerial photographic survey conducted between 1954 and 1956 over all the Italian territory. Based on this study, such a large set of historical aerial photographs can be exploited to produce DSMs at a resolution between 0.5 and $1 \mathrm{~m}$ with errors close to $2 \mathrm{~m}$ in elevation. Such an invaluable dataset could provide accurate high-resolution quantitative information on topography, which is of great value for multiple studies in Earth Science.

Author Contributions: S.S. performed the analysis and field surveys, I.M and M.S. conceived and designed the experiments, wrote the paper and analyzed the data; M.C. and A.C.M. contributed materials and revised the manuscript

Conflicts of Interest: The authors declare no conflict of interest. 


\section{References}

1. Godone, D.; Garbarino, M.; Sibona, E.; Garnero, G.; Godone, F. Fotogrammi storici, uno strumento per rappresentare l'italia che cambia. In Bollettino Dell'Associazione Italiana di Cartografia; EUT Edizioni Università di Trieste: Trieste, Italy, 2011.

2. Pulighe, G. Ortorettifica di foto e aree storiche per lo studio delle dinamiche ambientali in regioni montane. GEOmedia 2009, 13, 3.

3. Nocerino, E.; Remondino, F. Uso consapevole di software speditivi per la ricostruzione 3D. GEOmedia 2016, 20, 40-42.

4. Remondino, F.; Pizzo, S.D.; Kersten, T.P.; Troisi, S. Low-Cost and Open-Source Solutions for Automated Image Orientation-A Critical Overview. In Progress in Cultural Heritage Preservation; Lecture Notes in Computer Science; Springer: Berlin/Heidelberg, Germany, 2012; pp. 40-54.

5. Mertes, J.R.; Gulley, J.D.; Benn, D.I.; Thompson, S.S.; Nicholson, L.I. Using structure-from-motion to create glacier DEMs and orthoimagery from historical terrestrial and oblique aerial imagery. Earth Surf. Process. Landf. 2017, 42, 2350-2364.

6. Jaud, M.; Passot, S.; Le Bivic, R.; Delacourt, C.; Grandjean, P.; Le Dantec, N. Assessing the Accuracy of High Resolution Digital Surface Models Computed by PhotoScan ${ }^{\circledR}$ and MicMac ${ }^{\circledR}$ in Sub-Optimal Survey Conditions. Remote Sens. 2016, 8, 465.

7. Duarte, L.; Teodoro, A.C.; Moutinho, O.; Gonçalves, J.A. Open-source GIS application for UAV photogrammetry based on MicMac. Int. J. Remote Sens. 2017, 38, 3181-3202.

8. Benassi, F.; Dall'Asta, E.; Diotri, F.; Forlani, G.; Morra di Cella, U.; Roncella, R.; Santise, M. Testing Accuracy and Repeatability of UAV Blocks Oriented with GNSS-Supported Aerial Triangulation. Remote Sens. 2017, 9, 172.

9. Remondino, F.; Spera, M.G.; Nocerino, E.; Menna, F.; Nex, F.; Gonizzi-Barsanti, S. Dense image matching: Comparisons and analyses. In Proceedings of the 2013 Digital Heritage International Congress (DigitalHeritage), Marseille, France, 28 October-1 November 2013; Volume 1, pp. 47-54.

10. Bakker, M.; Lane, S.N. Structure from Motion (SfM) photogrammetry applied to historical imagery: Plug \& play? Remote Sens. 2017, 19, 10446.

11. Ince, D.C.; Hatton, L.; Graham-Cumming, J. The case for open computer programs. Nature 2012, $482,485$.

12. Minelli, A.; Oggioni, A.; Pugnetti, A.; Sarretta, A.; Bastianini, M.; Bergami, C.; Aubry, F.B.; Camatti, E.; Scovacricchi, T.; Socal, G. The project EcoNAOS: Vision and practice towards an open approach in the Northern Adriatic Sea ecological observatory. Res. Ideas Outcomes 2018, 4, e24224,

13. Mölg, N.; Bolch, T. Structure-from-Motion Using Historical Aerial Images to Analyse Changes in Glacier Surface Elevation. Remote Sens. 2017, 9, 1021.

14. Rupnik, E.; Daakir, M.; Pierrot Deseilligny, M. MicMac-A free, open-source solution for photogrammetry. Open Geospat. Data Softw. Stand. 2017, 2, 14.

15. Istituto Geografico Militare Italiano Sample of Aerial Photograph. Available online: https://www.igmi. org/geoprodotti/foto-aeree/1954/TIFF_800_DPI_non_fotogrammetrico/fotogramma-1484563254.8 (accessed on 15 March 2018).

16. Deseilligny, M.P.; Cléry, I. Apero, an open source bundle adjusment software for automatic calibration and orientation of set of images. In Proceedings of the ISPRS Symposium, 3DARCH11, Trento, Italy, 2-4 March 2011; Volume 269277.

17. Santangelo, M.; Marchesini, I.; Bucci, F.; Cardinali, M.; Fiorucci, F.; Guzzetti, F. An approach to reduce mapping errors in the production of landslide inventory maps. Nat. Hazards Earth Syst. Sci. 2015, 15, 2111-2126.

18. Nocerino, E.; Menna, F.; Menna, F. Multi-temporal analysis of landscapes and urban areas. ISPRS 2012, XXXIX-B4, 85-90.

19. Pulighe, G.; Fava, F. DEM extraction from archive aerial photos: Accuracy assessment in areas of complex topography. Eur. J. Remote Sens. 2013, 46, 363-378.

20. Pontius, R.G.; Thontteh, O.; Chen, H. Components of information for multiple resolution comparison between maps that share a real variable. Environ. Ecol. Stat. 2008, 15, 111-142.

(C) 2018 by the authors. Licensee MDPI, Basel, Switzerland. This article is an open access article distributed under the terms and conditions of the Creative Commons Attribution (CC BY) license (http:/ / creativecommons.org/licenses/by/4.0/). 